\title{
Eco-innovation opportunities in the waste management sector in Scotland
}

Juliette O'Keeffe

This is the accepted manuscript of the book chapter:

O'Keeffe, J. 2017. Eco-innovation opportunities in the waste management sector in Scotland. In B. D'Arcy, L.-H. Kim \& M. Maniquiz-Redillas (eds). Wealth creation without pollution: designing for industry, ecobusiness parks and industrial estates. IWA Publishing, London, pp. 89-98.

(C) IWA Publishing 2017 


\title{
2.3 ECO-INNOVATION OPPORTUNITIES IN THE WASTE MANAGEMENT SECTOR IN SCOTLAND
}

\author{
Juliette O'Keeffe \\ Division of Environmental Engineering and Systems Visualisation, \\ Abertay University, Bell Street, Dundee, DD1 1HG. \\ E-mail: j.o'keeffe@abertay.ac.uk
}

\begin{abstract}
Creating more circular economies that retain and recirculate the value of resources within an economy is gaining significant attention, with the concept of industrial symbiosis assisting businesses to reduce resource leakage from local economies. An eco-industrial park applies industrial symbiosis on the scale of an industrial park and may incorporate additional features such as shared infrastructure and services that assist in reducing environmental impacts and improving resource efficiency. This paper provides an overview of the application of the industrial symbiosis concept in Scotland and presents findings of the ACE Eco-Partnerships project, which attempted to identify and develop opportunities for industrial symbiosis in the Tayside and Fife region of Scotland, particularly on the scale of eco-industrial parks. The paper provides reflection on some of the barriers to eco-industrial park development, with specific reference to "retrofitting" industrial symbiosis onto existing industrial parks versus developing new ecoindustrial parks.
\end{abstract}

\subsubsection{Introduction:}

In the transition to low carbon and more sustainable economic models, one of the primary challenges facing future waste and resource management systems is the shift away from a flow of materials from use to final disposal, to a system that retains and maximises the use of resources within the economy. The circular economy (CE) approach recognises that the supply of global resources is finite and dwindling, therefore seeks to maximise the use of resources in a circular "beginning to beginning" approach as opposed to a linear "beginning to end" approach by optimising the lifespan and multiple uses of a single resource over time. The World Economic Forum and the Ellen MacArthur Foundation have produced a comprehensive review of the economic potential of a CE and estimate that over US $\$ 1$ trillion in cost savings could be made by 2025 by adopting new approaches to resource flows throughout the supply chain (World Economic Forum 2014). To achieve these savings, such approaches would require participation by a large number of diverse groups across the economy including the waste and resource management sector, manufacturers, product designers, consumers and energy producers. Although these models envisage a global coming together of participants across the economy, practical and feasible interactions are also possible on a local scale. The eco-industrial park concept is one model for applying industrial symbiosis on a local level. The concept, and its application in Scotland, is discussed further in the following sections.

\subsubsection{About Industrial Symbiosis}

As described by Boons et al. (2011), industrial symbiosis (IS) refers to "the material and energy flows and transformations that are generated by economic actors within a geographically bound system". Generally, IS involves the exchange of by-products of processes between co-located entities for mutual benefit. Chertow (2008) states that there are three areas where resource exchange may take place between industry: by-product exchange; utility or infrastructure sharing; and joint provision of services. Chertow distinguishes IS from normal exchanges, for example between a single organisation and a recycler by suggesting that in order to meet the definition of IS, three or more organisations should be involved in the exchange of two or more resources. This can include energy, heat or materials with the result being the net minimisation of waste and resource consumption. The IS approach can assist organisations in meeting regulatory requirements in areas such as waste disposal, carbon reduction or water effluent release. 
Commonly the condition of co-location or geographical proximity is required for IS to occur, as noted by Boons et al. (2011). The extent of this geographical boundary however is not well defined. Jensen et al. (2011) suggest that for simple materials exchanges, the definition of 'in proximity' may depend on "the spatial distribution of industrial diversity" in the region. Jensen et al. (2011) mapped out exchange distances for 792 material exchanges between organisations participating in the UK's National Industrial Symbiosis Programme (NISP) to December 2009. They found that across all exchanges there was an average resource movement of 20.4 miles, suggesting that the extent of industrial diversity in the UK is approximately 20 miles, the distance across which at least half of all industrial exchanges should be possible (Jensen et al. 2011). Geographical proximity of a much reduced distance is necessary if the symbiosis involves the sharing of infrastructure and services. Such exchanges measured by NISP accounted for approximately 187 of 979 identified exchanges. These included synergies such as sharing of land, labour, or logistics, many of which must occur within a much closer proximity. These types of synergies in combination with material exchanges can form the basis for an eco-industrial park development.

\subsubsection{The eco-industrial park concept}

Industrial parks provide ideal locations for IS opportunities to be developed, particularly where industry involved in manufacturing, recycling, or energy production is located in close proximity. These locations provide opportunities for not only material exchanges, but also for shared services and infrastructure including surface water treatment, process and wastewater treatment as well as sharing of expertise, labour and logistics. The application of IS on an industrial park level, where many participants are involved in multiple exchanges of resources, may be termed an eco-industrial park (EIP). Although various definitions exist to describe an EIP, it is generally understood that there is a geographical grouping of businesses that, as defined by Lowe (2001) "seek enhanced environmental, economic and social performance through collaboration in managing environmental and resource issues". Therefore multiple IS exchanges between businesses on the park are likely to be occurring and additional features may exist such as sustainable buildings, pollution control measures, shared services and sustainable infrastructure (Lowe 2001, Chertow 2008). Lowitt and Cote (2013) suggest that the definition of an EIP can range from a vision based on efficient use of materials and energy to one that takes a broader view of incorporating additional factors such as the local ecology, water and air management. Lowe (1997) describes a number of strategies for developing an eco-industrial park that include incorporating features such as onsite waste management functions, designs that maximises the efficient use of energy, water, and incorporates renewables, and eco-friendly materials, systems for communications between organisations and managing joint aspects of the park such as maintenance of infrastructure and provision of services.

The development of EIPs can be a spontaneous and organic process built up by tenant businesses on an industrial estate, or can be pre-planned from a defined vision. The most commonly cited example of IS applied on an industrial park scale is that of Kalundborg, in Denmark, where a coal fired plant exchanges heat, steam, fly ash and waste gypsum with a range of other co-located organisations. The formation of the Kalundborg EIP was not pre-planned, but rather developed over time as the need to find outlets for industrial by-products for a large coal-fired plant and the availability of cheap resources encouraged company interactions (Lowe 1997; Chertow 2008). This was a gradual development based on business need but has inspired planners, authorities, businesses and researchers to explore ways of either building new EIPs from a pre-envisioned network of symbiotic connections or retrofitting existing industrial parks with new IS interactions in order to deliver economic and environmental benefits (Behera et al. (2012). The remainder of this paper reviews the outcomes of a European Regional Development Fund (ERDF) project delivered in Tayside, Scotland to explore the possibility of building EIPs in the region. The case study illustrates some of the difficulties developers may experience both in attempting to retrofit an EIP concept onto an existing industrial park, and creating a new park.

\subsubsection{Case Study: Industrial Symbiosis and Eco-Park development in the East of Scotland}




\subsubsection{Background to ACE Eco Partnerships:}

At an EU level, environmental legislation has been driving change in all member states to improve environmental quality and reduce carbon emissions. Directives such as the Water Framework Directive, the EU Landfill Directive, and the Renewables Directive (2009/28/EC) have led member states to introduce new regulation in order to contribute to achieving EU wide targets. Scotland has declared ambitious targets for improving water quality (Water Environment and Water Services (Scotland Act 2003), reducing emissions (Climate Change Scotland (Act) 2009), and diverting waste from landfill (Waste (Scotland) Regulations, 2012). Therefore the policy environment for businesses seeking to improve their environmental impacts has been supportive, including government funding being made available for support agencies and development projects designed to stimulate opportunities for IS. The ACE Eco-Partnerships project, hosted by Abertay University in Dundee, Scotland, received part funding through the ERDF in 2008 to investigate opportunities for IS and the potential to create an EIP in the Tayside and Fife region of Scotland. The project investigated both the retrofit of an EIP on an existing park and the development of a new EIP from a pre-envisioned collection of businesses

\subsubsection{Scoping for retrofit EIP development potential on existing industrial estates}

The difficulty in applying the EIP concept to existing industrial estates is the lack of initial planning, siting of tenants and pre-defined industrial symbioses that may exist on a new EIP development.

The ACE Eco-Partnerships project carried out scoping studies of industrial estates in the East of Scotland (Tayside and Fife) to identify those that could potentially benefit from the application of an EIP concept, and where synergistic relationship between tenants already existed, or could easily be identified. In order to do this, the project consulted local maps of industrial estates showing existing tenants, consulted local economic development information for the locality, and examined potential environmental issues that could be overcome more effectively by building partnerships between the tenant businesses. Site visits were also carried out to identify important features of the site for consideration in evaluating EIP development potential. Categorisation of business types by sector or activity was carried out to identify the types of waste production likely across the site, the level and type of energy demand (space heating, process), any manufacturing present and the types of resource inputs, and other resource or environmental management issues that may be present.

Using this information, the project team nominated industrial estates that would be most likely to benefit from a collective approach to environmental issues such as waste, energy or water treatment, for further investigation and study. Tenant businesses were contacted and offered a free resource efficiency audit in order to entice them to participate. Those businesses that accepted were visited and interviewed about their existing levels of resource consumption and wastage and any additional environmental matters such as process emissions to air or water. This process revealed one of the primary difficulties with retrofitting the EIP concept onto existing industrial sites. Although there was some uptake by businesses interested in resource efficiency audits, the majority of businesses were either unwilling or uninterested in participating. Those that did participate were struggling either with waste and energy costs or environmental compliance of some nature. Although these businesses were interested in identifying improvements to their own site and processes, there was much less willingness to consider joint measures with other tenant businesses.

Another issue encountered by the project team was the high percentage of site tenants that did not own the building or the land where they were operating. This reduced interest in investing in updates or improvements to infrastructure that would have potential longer term environmental benefits. The owneroccupier businesses also showed some reluctance to enter into joint agreements with non-owner-occupiers, whose tenancy on the industrial estate was seen as potentially transient. A dilemma faced by factor organisations or site owners was that any improvements to infrastructure to reduce existing environmental impacts would be based upon the current tenancies, however these were not fixed, and changes may not suit future tenants in all cases. 
Despite these difficulties, there was some willingness amongst participants to consider where working with others could have a mutual benefit. In particular economies of scale could be realised in the area of waste management to allow for recycling to be taken up economically for a specific waste stream if working in partnership with others. In addition, the correct mix of site owners and business types can have a marked effect on whether the businesses may consider working in a more symbiotic relationship. A high concentration of long term tenants and/or owner-occupiers, coupled with businesses involved in manufacturing or processing are better suited to EIP retrofit as compared to sites where large numbers of business units show regular turnover in tenants and where businesses are primarily linked to retail, wholesale or distribution activities. Where the local authority provided support for co-ordinating or highlighting opportunities to local businesses, there appeared to be greater support from businesses to consider EIP development opportunities.

\subsubsection{Scoping for potential EIP on new sites, or single tenant sites.}

The ACE Eco-partnerships project carried out a review of a small number of identified sites where an existing anchor tenant was interested in exploring opportunities to develop a new EIP. Three sites were investigated in some detail to propose how an EIP development could progress. These locations were identified as potential EIP locations where either limited or no economic activity was currently taking place. Each location was visited by the project team and discussions focused on the potential redevelopment of the sites into EIPs utilising the theory of IS.

A site evaluation was carried out for each site that considered factors of relevance for EIP development such as the geographical location of the site, existing linkages to other businesses, main transport routes, and connection to electricity and gas grid and sewer connections. Characteristics of the site also helped to identify the relevant features and technologies that could be incorporated on the site, such as potential renewable energy technologies, or requirement for contaminated land or effluent treatment. Proximity to existing large industry was also considered as potential partners in developing a site as well as proximity to residential neighbours as potentially impacted by a development (i.e. due to noise, odour, vehicular movement, or as an end-market for resources such as heat).

\subsection{Site A:}

Site A was a former industrial site that had been vacant for approximately five years. The site owner was interested in the EIP concept, and planned to redevelop the site to include a range of economic activity. The 42 acre site was previously used for industrial activities over the past two centuries but at the time of the site investigation was somewhat isolated in terms of proximity to other active industrial activities. The site benefited from close proximity to transport linkages including major road networks connecting to Scotland's central belt and the potential for a rail connection nearby, in addition to proximity to the River Forth. The site also had connection to mains services and an existing wastewater treatment facility onsite. The site owner was interested in the types of IS synergies that could be developed, with the potential to create added value partnerships by the careful selection of tenants. The site owner was already involved in waste collection and recycling, and was therefore interested in the potential industries that could co-locate to manufacture products from recovered waste materials. In addition, the potential to generate energy onsite from waste using anaerobic digestion of organic waste materials was of interest, providing future tenants with a high heat and electricity demand with an onsite source of energy. A number of promising strategies were discussed with the company, including the potential to attract co-locating businesses involved in reprocessing or remanufacture, as well as other potential tenants with high heat demand that would benefit from access to heat from an anaerobic digestion plant.

Despite a number of potential strategies being proposed and initial enthusiasm by the developer, a number of barriers to EIP development existed. The proximity of neighbouring residential properties could potentially restrict some of the industrial activities that could take place due to noise, odour or other nuisance issues. Due to the fact the site had been an industrial facility for the past two centuries at least, it was likely that this barrier could be overcome and the proximity of residential properties could potentially provide an end market for renewable heat or electricity generated onsite. In order for redevelopment to occur, the developer would have to consider the historic site contamination in great detail, with the possible need to 
remediate some areas of ground, and either rebuild or extensively refurbish existing buildings. Many of the structures onsite would needed to be demolished or refurbished in order to be suitable for future tenants. A barrier to the development was therefore the high level of cost involved in rejuvenating the site to an acceptable standard, and attracting companies to co-locate specifically based on sharing and exchange of resources onsite. Envisaging the potential infrastructure needs with respect to electricity, heat, water and wastewater services was also difficult without knowing the needs of potential tenants in advance. The developer was therefore faced with the dilemma of how to invest in EIP infrastructure from the outset in order to attract the "right" kind of businesses to co-locate. Unfortunately the site suffered a large fire in December 2012 that has affected further development. The costs of remediating and rebuilding on the site have delayed any further progress at this point.

\subsection{Site B:}

Site B was a former military site with limited existing structures but with ample space for development close to Perth. The site owner was interested in the EIP concept however, with no existing activities taking place on the site, any proposed EIP would be based on attracting a suitable collection of tenant businesses. As the site was a blank canvas, the potential for development ideas was endless. Without an existing anchor tenant, or identified demand from industry for occupying the space, defining a focus for the types of businesses and potential synergies that could take place on the site was difficult. In order to consider how to attract businesses, a review was undertaken to recommend features of a development that would encourage businesses to relocate. This included features such as shared resource and waste management facilities and collection schemes, potential interconnection of units to allow sharing of resources, and an overall ecofriendly design to the development incorporating green infrastructure features to minimise the impact of future development and business activities on the environment.

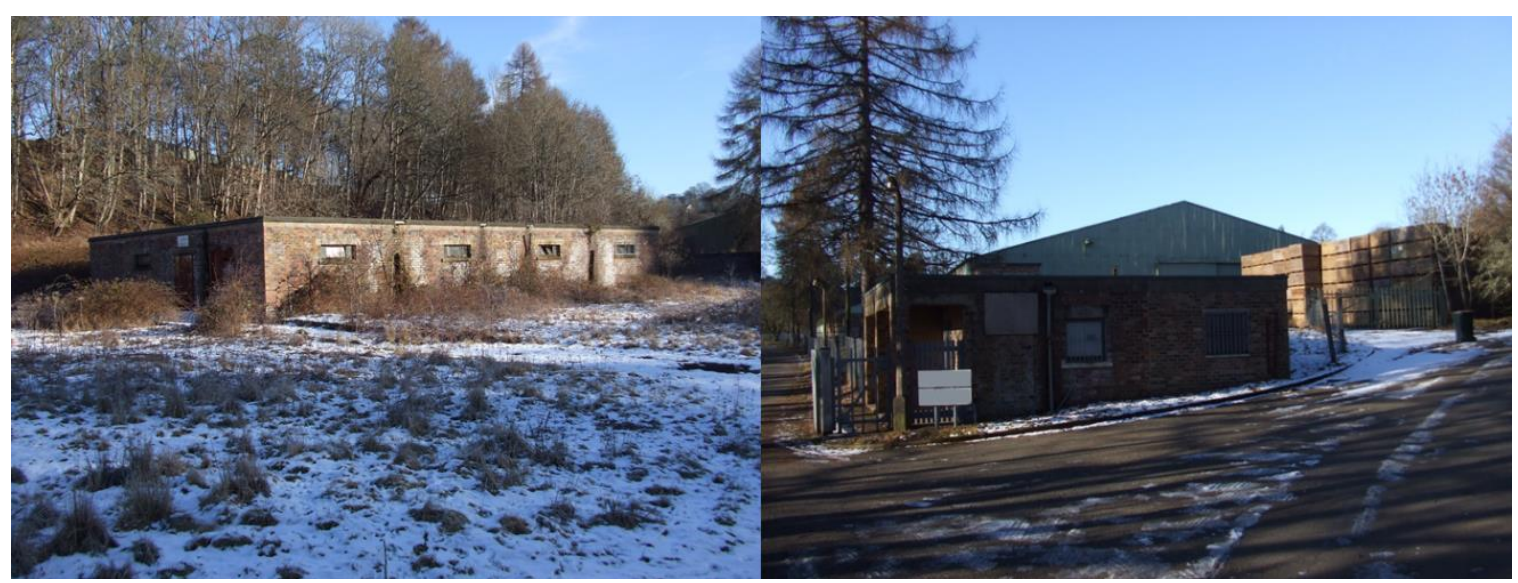

Figure 2.3.1 Site B: Derelict site formerly used for military purposes. (Photo courtesy of Urban Water Technology Centre)

The difficulty in proposing an EIP design was identifying the types of businesses likely to co-locate and the features that would allow other businesses to interact in a synergistic manner. Any development on the site would potentially suffer from a lack of existing tenants. In order for industrial synergies to occur, the site owner would be reliant upon potentially synergistic businesses seeking tenancy in the industrial park at the same time. Although encouragement could be provided in terms of infrastructure, or discounts/incentives to the "right" kind of businesses, there would be no guarantee that any business would choose to locate in the site. This approach EIP development attempts to pre-determine the types of IS that may emerge and seek out potential businesses that match the profile. This can impose limitations on the development, and assumes all potential actors will participate in developing collective solutions. This strategy can be made easier by focussing on regional strengths and economic development needs or drivers, or seeking out business groupings rather than attracting businesses on an individual basis to locate on the site.

\subsection{Site C:}


Site $\mathrm{C}$ was an existing waste management site, located near to agricultural land, with an existing landfill and composting facility onsite. The site owners employed a consultant/project manager specifically to explore the idea of developing an EIP on the site. The presence of an existing waste management facility and composting facility, including food waste recycling onsite, helped the consultant to identify a number of potential synergistic businesses to target for co-location and the beginning of an EIP.

The location of the site between Fife and Perth was relatively remote, with little potential for impact upon residential areas. The site itself had experienced land contamination issues in the past related to the operation of the waste management facility, and was still regularly monitored for impacts on the local aquatic environment and vegetation. Future development could enhance infrastructure in order to incorporate additional features to protect the aquatic environment from pollution impacts related to business activity on the site.

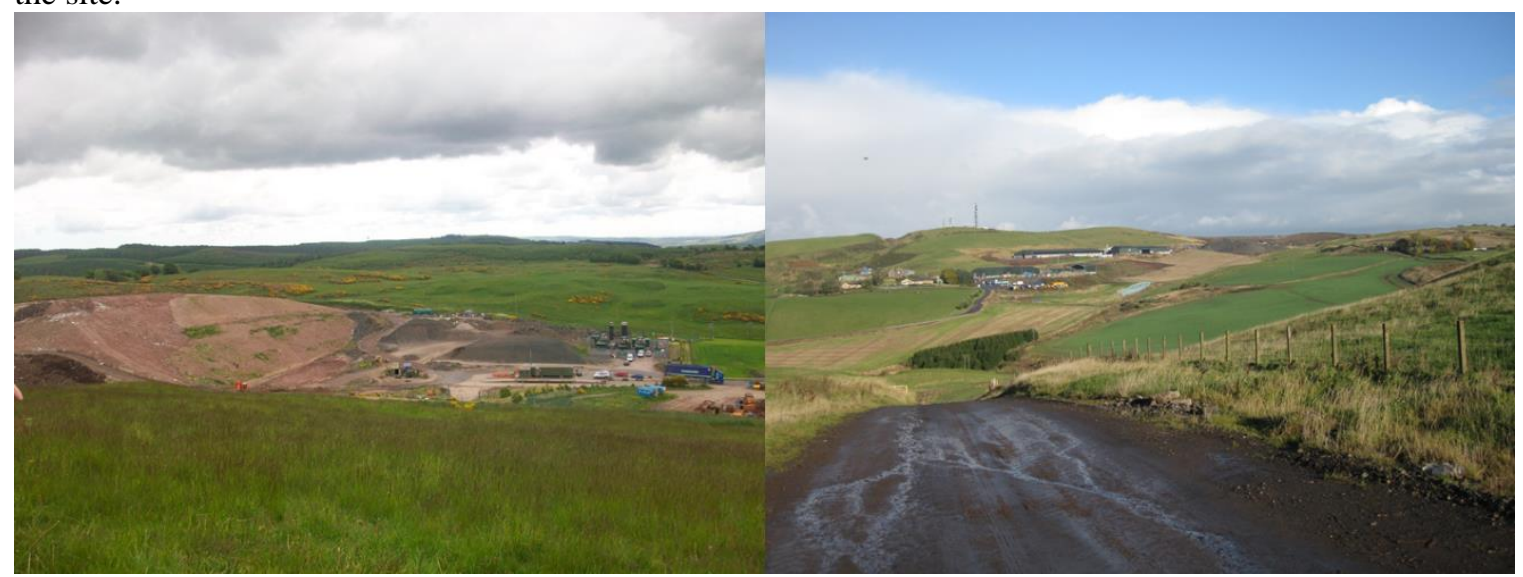

Figure 2.3.2 Site C: Occupied waste management site in proximity to area of agricultural use. (Photo courtesy of Urban Water Technology Centre)

The most promising area to begin developing EIP synergies on the site was in relation to the processing of food waste. It was observed that the high value compost from the composting of food waste could be utilised locally as a medium for local food growing, particularly high value food items to be grown in green houses. The site also had significant potential for energy generation from a range of sources that the site owner was considering including wind, anaerobic digestion and a waste to energy thermal plant. The production of energy onsite would be particularly beneficial if tenants could utilise the energy directly rather than exporting it offsite. This was particularly true for heat, exploring the potential for co-locating industry with a heat demand (such as greenhouse food growing). In addition, as a waste management facility, there was also potential to segregate materials such as plastics in order to provide a feedstock to complementary manufacturing businesses to establish production units.

The site is currently still in the process of forming ideas and attempting to attract complementary businesses to co-locate. ACE Eco-partnerships assisted the developer in exploring the requirements and complexities of many aspects of the development. There has been limited interested in outside businesses seeking to co-locate on the site. Although the site may provide a convenient location for onsite energy generation, food production and potentially manufacturing from recycled waste, there are issues that limit the attractiveness of the location for new tenants. The relative remoteness and distance from major transport routes adds logistical costs to any manufacturers or food producers seeking to distribute products and the lack of existing infrastructure for business units limits the attractiveness of the site to potential tenants, and their workforce. These barriers may be overcome as tenants begin to occupy the site, and development allows for the improvement of local infrastructure, and increased attractiveness to additional co-locating businesses. 2.3.3.4 Case Study Summary:

When identifying potential EIP developments, the existing collection of activities on the site, the geographical location and state of the site, and the presence or absence of existing businesses all affect the ability of an EIP to develop. The following table presents some of the advantages and disadvantages of each site with respect to possible EIP development. 
Table 2.3.1 Summary of key advantages and disadvantages to EIP development at the Case Study sites.

\begin{tabular}{|c|c|c|}
\hline Site & Key advantages & Key disadvantages \\
\hline $\begin{array}{l}\text { Existing industrial parks } \\
\text { reviewed for EIP } \\
\text { retrofitting }\end{array}$ & $\begin{array}{l}\text { - } \quad \begin{array}{l}\text { Presence of existing tenants } \\
\text { - }\end{array} \text { Knowledge of the current level of } \\
\text { demand for energy, waste and } \\
\text { water services } \\
\text { - Some existing infrastructure } \\
\text { already, and logistical/transport } \\
\text { links may already be established }\end{array}$ & $\begin{array}{l}\text { - } \quad \text { Transient nature of industrial } \\
\text { estate tenants } \\
\text { - May suffer from the "wrong" } \\
\text { type or collection of businesses, } \\
\text { such as those with low levels of } \\
\text { need with respect to energy, } \\
\text { water, and waste services, and } \\
\text { therefore less likely to partake } \\
\text { in EIP collective solutions. }\end{array}$ \\
\hline Site A: Ex-industrial site & $\begin{array}{ll}\text { - } & \text { Large anchor tenant involved in } \\
\text { materials reprocessing } \\
\text { - } \quad \text { Good connection to services } \\
\text { - } \quad \text { Large space and convenient } \\
\text { location for additional } \\
\text { businesses to co-locate }\end{array}$ & 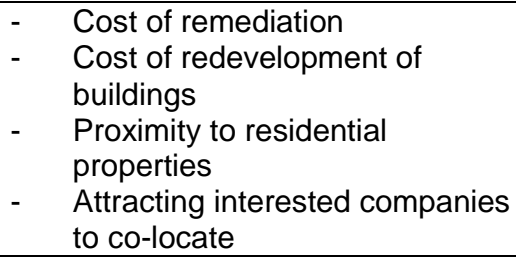 \\
\hline $\begin{array}{l}\text { Site B: Former military } \\
\text { site }\end{array}$ & $\begin{array}{ll}\text { - } & \text { Large space and convenient } \\
\text { location } \\
\text { - }\end{array}$ & $\begin{array}{l}\text { - } \quad \text { No existing tenants, therefore } \\
\text { no pre-defined synergies to } \\
\text { develop } \\
\text { Making an EIP "fit" would } \\
\text { depend on willing businesses } \\
\text { co-locating and agreeing to } \\
\text { work synergistically }\end{array}$ \\
\hline $\begin{array}{l}\text { Site C: Rural waste } \\
\text { management site }\end{array}$ & $\begin{array}{l}\text { - } \quad \text { Large remote space } \\
\text { - Supply of waste materials to } \\
\text { supply recycling or } \\
\text { manufacturing activities } \\
\text { - Ability for renewable energy } \\
\text { development onsite to provide } \\
\text { potential tenants with low carbon } \\
\text { heat and electricity }\end{array}$ & $\begin{array}{ll}\text { - } & \text { Remoteness of site may limited } \\
\text { attractiveness of some } \\
\text { businesses } \\
\text { - } \quad \text { Inability to attract } \\
\text { complementary businesses } \\
\text { - Existing pollution and } \\
\text { contamination issues, and need } \\
\text { for improved infrastructure }\end{array}$ \\
\hline
\end{tabular}

Although EIP development potential existed on all sites visited, establishing a new EIP is a complex process. Where an anchor tenant already occupies, or owns the site, it is easier to begin to envisage potential synergies and the types of businesses that would benefit from relocation to the site. There are limitations with these sites such as the location and attractiveness of the site to new tenants. The promise of access to resources in the form of feedstock or energy may be attractive, but businesses may also wish to be in locations that are accessible and appealing to potential customers and the workforce. For a new site with no existing tenants, a major limitation in establishing EIPs is finding synergistic businesses that are looking to relocate at the same time. It is difficult to pre-envisage the types of synergies likely to occur, and simultaneously identify businesses willing to relocate and take up tenancy in newly designed eco-parks.

\subsubsection{Discussion}

The ACE Eco-Partnerships project example has highlighted some of the difficulties in establishing new EIPs. There are a number of theories as to why any individual eco-industrial park projects may not succeed. Boons and Spekkink (2012) define five factors that are relevant to creating ideal conditions for IS to occur:

1. Learning and strategic vision

2. Issues related to the diversity of actors involved

3. Trust

4. Anchor tenants or coordinating bodies

5. An enabling context (i.e. policy, regulation, structures, culture etc.) 
Boons and Spekkink (2012) analysed these factors in the context of institutional capacity, including relational capacity, knowledge capacity and mobilisation capacity and found that relational capacity (strengthening the network collaborators and partners, building trust and evaluating risks and opportunities) and knowledge capacity (awareness of the opportunities for IS and what is realistically feasible, and what tools and resources may be available) were not significantly linked to successful IS developments. Mobilisation capacity, however, (the ability of actors to engage with external actors, influence policy or regulation and to draw in resources from external sources) was significantly linked to successful IS measures. This theory is supported by the observations made in the ACE Eco-partnerships project. Of the three sites investigate for new EIP development, only Site C could be observed to have strong mobilisation capacity, and was also observed to be the EIP development most likely to go ahead of all those studied in the region. Through the ACE Eco-Partners project, the relational capacity and knowledge capacity of organisations was improved, however, without the ability to act on, or mobilise, these aspects of improved institutional capacity the developments have yet to go ahead.

Interestingly both Site $\mathrm{A}$ and Site $\mathrm{C}$ investigations were initiated by waste management companies. In the context of current waste policy and thinking on the circular economy, a waste management firm as an anchor tenant for an EIP could provide a strong foundation around which development could take place. Waste firms focussed more on waste collection and transport may not be fully subscribed to maximising the benefits of IS compared to firms also involved in sorting, processing and developing partnerships with endmarkets. While the supply of recyclate is increasing, the capacity to process materials within Scotland has not fully developed (O'Keeffe and Gilmour, 2012). Closing resource loops in Scotland remains challenging with large quantities of recyclate being exported out of Scotland and often out of the UK. Eco-industrial park developers seeking to improve mobilisation capacity will need to address this issue and lobby government to stimulate end-markets for waste. In order to achieve this, issues related to quantity of recyclate, the availability of processing facilities and technologies and end markets for recycled content products need addressed (O'Keeffe and Gilmour, 2012).

\subsubsection{Conclusion:}

Eco-industrial park development has the potential to improve the efficiency of industrial operations from waste management to manufacturing to energy production, and provide added benefits to businesses in terms of reduced resource management costs and improved environmental credentials. Developing EIPs requires willing participants, the opportunity for synergistic interactions, and the ability for actors to implement the necessary interventions to allow synergies to develop. Although EIP development is largely business led, local authorities can assist the process by providing local businesses with information and examples of best practices and, on local authority owned sites, support collective solutions that support business and protect the environment.

\subsubsection{References:}

Behera, S.K., Kim, J., Lee, S., Suh, S., Park, H. (2012). Evolution of 'designed' industrial symbiosis networks in the Ulsan Eco-industrial Park: 'research and development into business' as the enabling framework. Journal of Cleaner Production. 29-30, 103-112.

Boons, F., Spekkink, W. and Mouzakitis, Y. (2011). The dynamics of industrial symbiosis: a proposal for a conceptual framework based upon a comprehensive literature review. Journal of Cleaner Production. 19, 905-911.

Boons, F and Spekkink, W. (2012). Levels of Institutional Capacity and Actor Expectations about Industrial Symbiosis. Journal of Industrial Ecology. 16(1), 61-69.

Chertow, M.R. (2008). "Uncovering” Industrial Symbiosis. Journal of Industrial Ecology. 11(1), 11-30.

Jensen, P., Basson, L., Hellawell, E., Bailey, M., Leach, M. (2011). Quantifying 'geographic proximity': Experiences from the United Kingdom's National Industrial Symbiosis Programme. Resources, Conservation and Recycling. 55, 703-712.

Lowe, E.A. (1997). Creating by-product resource exchanges: Strategies for eco-industrial parks. Journal of Cleaner Production. 5(1-2), 57-65.

Lowe, E.A. (2001). Eco-industrial Park Handbook for Asian Developing Countries. Indigo Development, Oakland, CA. Lowitt, P. and Côté, R. (2013). Putting the Eco into Eco Parks. Journal of Industrial Ecology. 17(3), 343-344. 
O'Keeffe, J. and Gilmour, D. (2012). Eco-innovation drivers and barriers in the waste management sector in Scotland. In: Proc. of the $18^{\text {th }}$ Annual International Sustainable Development Research Conference, University of Hull, Hull, 24-26 June.

World Economic Forum. (2014). Towards a Circular Economy.

http://www3.weforum.org/docs/WEF ENV TowardsCircularEconomy Report 2014.pdf (accessed 22 June 2015). 